\title{
Impact of Additional Extracranial Injuries on Outcome after Mild Traumatic Brain Injury
}

\author{
MAJA STULEMEIJER, ${ }^{1,2}$ SIEBEREN P. VAN DER WERF, ${ }^{1}$ BRAM JACOBS, ${ }^{2}$ JAN BIERT, ${ }^{3}$ \\ ARIE B. VAN VUGT, ${ }^{3}$ JOLANDA M.P. BRAUER, ${ }^{2}$ and PIETER E. VOS $^{2}$
}

\begin{abstract}
Many patients with mild traumatic brain injury (MTBI) concurrently sustain extracranial injuries; however, little is known about the impact of these additional injuries on outcome. We assessed the impact of additional injuries on the severity of postconcussional symptoms (PCS) and functional outcome 6 months post-injury. A questionnaire (including the Rivermead Post-Concussion Questionnaire and SF-36) was sent to consecutive MTBI patients (hospital admission Glasgow Coma Score 13-15; age range 18-60 years) admitted to the emergency department of a level-I trauma center, and, to serve as a baseline for PCS, a control group of minor-injury patients (ankle or wrist distortion). Of the 299 MTBI respondents (response rate 52\%), 89 had suffered additional injuries (mean Injury Severity Score [ISS] of $14.5 \pm 7.4$ ). After 6 months, 44\% of the patients with additional injuries were still in some form of treatment, compared to $14 \%$ of patients with isolated MTBI and 5\% of the controls. Compared to patients with isolated injury, MTBI patients with additional injuries had resumed work less frequently and reported more limitations in physical functioning. Overall, they did not report higher levels of PCS, despite somewhat more severe head injury. Regardless of the presence of additional injuries, patients that were still in treatment reported significantly more severe PCS, with highest rates in patients with isolated MTBI. In conclusion, many patients with additional extracranial injuries are still in the process of recovery at 6 months after injury. However, despite more severe impact to the head and inferior functional outcomes, these patients do not report more severe PCS.
\end{abstract}

Key words: head injury; mild traumatic brain injury; multiple trauma; outcome; post-concussion symptoms

\section{INTRODUCTION}

W ITH AN INCIDENCE of 100-300 per 100,000 hospital-treated patients, mild traumatic brain injury (MTBI) is one of the most prevalent neurological disorders. Mortality is low, and most patients are able to regain their former level of functioning within 3 months (Cassidy et al., 2004). Nevertheless, a subgroup of pa- tients still reports debilitating symptoms up to years after injury, and there is ongoing controversy regarding the mechanisms that cause these chronic postconcussional symptoms (Binder et al., 1997; Cassidy et al., 2004; King et al., 1999; Mooney et al., 2005). A factor that may greatly delay the process of recovery after MTBI is the presence of concurrently sustained injuries to other parts of the body such as luxations, fractures, or internal le-

Departments of ${ }^{1}$ Medical Psychology, ${ }^{2}$ Neurology, and ${ }^{3}$ Surgery, Radboud University Nijmegen Medical Centre, Nijmegen, The Netherlands. 


\section{STULEMEIJER ET AL.}

sions. However, little is known about the impact of these additional injuries on long-term outcome and, more specifically, the development of postconcussion-like symptoms.

Many studies excluded patients with (severe) extracranial injuries to avoid potential bias (Barth et al., 1983; Bohnen et al., 1995; de Kruijk et al., 2002; Hugenholtz et al., 1988; Levin et al., 1987; Macciocchi et al., 1998; McCauley et al., 2001). The few studies that did comment on the influence of non-brain injuries on outcome, either by including severity scores in a regression model (Bohnen et al., 1994; Dikmen et al., 1994; Savola et al., 2003) or by comparing TBI patients to general trauma patients without head injury (Dacey et al., 1991) consistently show that more severe additional injuries are associated with lower return-to-work rates, most likely reflecting slower physical recovery (Dikmen et al., 1994; Stambrook et al., 1990; van der Naalt et al., 1999). Several authors suggest that the presence of additional injuries might also lead to increased levels of postconcussion-like symptoms (e.g., through physical limitations, pain, or fatigability) (Binder, 1986; Iverson et al., 1997; Kibby et al., 1997; Satz et al., 1999), but this assumption has not often been the subject of systematic research, and current results are inconsistent. Whereas one study reports more cognitive and behavioral problems in patients with extracranial injuries compared to those without (van der Naalt et al., 1999), others only found more physical symptoms (Bohnen et al., 1994) or no influence of nonbrain injury severity on symptom report at all (Paniak et al., 2002; Savola et al., 2003).

To our knowledge, no studies have directly compared MTBI patients with and without additional injuries on long-term outcome or considered the impact of different types of additional injuries. As a result, the process of recovery of this category of patients is still poorly characterized. In the present study, we will evaluate MTBI patients with and without concurrently sustained extracranial injuries regarding functional outcome and postconcussional symptoms 6 months post-injury, and assess the impact of the nature and severity of the additional injuries. Furthermore, as many MTBI patients with additional injuries will still be in the process of recovery, treatment status at time of the assessment will be considered.

\section{METHODS}

\section{Patients and Procedure}

All consecutive patients aged 18-60 years who were admitted to the emergency department (ED) of the levelI trauma center of the Radboud University Nijmegen
Medical Centre with a diagnosis of MTBI in the period between November 2001 and October 2003 were eligible to participate in the study. Six months post-injury, all patients were sent a letter containing information about the study and a questionnaire booklet with a request to return the completed forms, together with a written informed consent. The study was approved by the ethics committee of the Radboud University Medical Centre Nijmegen.

\section{Definition of Mild Traumatic Brain Injury}

The definition of MTBI that we used was a history of impact to the head with or without loss of consciousness (LOC) of $\leq 30 \mathrm{~min}$ and with or without posttraumatic amnesia (PTA) and a hospital admission Glasgow Coma Score (GCS) of 13-15 (Vos et al., 2002).

\section{Parameters of Mild Traumatic Brain Injury}

As part of a standardized registration procedure, a range of clinical injury indices were recorded on admission to the ED (e.g., Glasgow Coma Scale [GCS], risk factors for intracranial complications and mechanism of injury). The presence and duration of LOC was based on reports of witnesses or ambulance personnel, and the presence and resolution of PTA was assessed by a resident of neurology on the ED by a series of questions regarding short-term memory and orientation. Computed tomography (CT) of the head was performed according to international guidelines (Vos et al., 2002). For the purpose of this study, CTs were classified as normal or abnormal, an abnormal CT was defined as showing signs of contusion, edema, subdural hematoma, epidural hematoma, or subarachnoid hemorrhage, according to one rater blinded from all outcome measures (P.V.). If alcohol or drug intoxication was suspected, a blood draw was conducted in the ED to determine blood-alcohol levels.

\section{Additional Injuries}

Injury severity was scored with the Abbreviated Injury Score (AIS)/Injury Severity Score (ISS) (Baker et al., 1974), an anatomical scoring system that provides an overall severity score based on the three most severely injured body regions. Patients were categorized as having additional injuries when, in addition to an MTBI, they sustained significant injury, defined as an AIS-score of 2 or more, in one of the AIS-ISS body regions. Two ISS scores were calculated-i.e., the AIS-ISS (based on all six AIS body areas) and a modified score (based on the three most severely injured body areas excluding injuries to the head). In this study, the location of the additional trauma was allocated to mutually exclusive AIS regions 


\section{IMPACT OF EXTRACRANIAL INJURIES ON MTBI OUTCOME}

(Face, Chest/Abdomen, Extremities, or Multiple [significant injury to more than one AIS region besides the head]). Because of few patients per category, the categories Chest and Abdomen were grouped together. Only one patient had a score of 2 on the AIS-External, and was consequently excluded from the subgroup analysis.

\section{Outcome Measures}

In addition to general questions about the patient's demographics, education, and rehabilitation status, the questionnaire booklet contained the following self-report scales:

- The Rivermead Post-Concussion Questionnaire (RPCQ) assessing 16 common post-concussional symptoms on a 5-point Likert scale. Patients are asked to rate how problematic, if at all, each symptom is experienced compared with the situation before they sustained their head injury (King et al., 1995). In the present study, symptoms were classified into three domains (physical, cognitive, affective), and given that the number of items per domain was unequal, raw scores were transformed into a 1-100 scale. The three symptom domains were highly internally consistent, with Cronbach's alpha reliability coefficients ranging from 0.88 to 0.92 . As the RPCQ rates symptom severity compared to before trauma, no population norms are available. Minor-injury orthopedic patients aged $18-60$, who attended the ED in the period between January and November 2003 with an ankle or wrist distortion without any sign of a head injury, in whom speedy recovery was expected, served as a control for the severity and specificity of the postconcussional symptoms.

- Two subscales of the Short Form-36 (Dutch version) to assess limitations in activities of daily living $(A D L)$ : "Physical functioning" (10 items measuring the extent to which a person is limited by his/her health in performing a range of physical activities, from playing strenuous sports to bathing and dressing) and "Social functioning" ( 2 items measuring the extent to which health or emotional problems impact on social activities with others). All items of each subscale are summed and the total is transformed into a 1-100 score, with higher scores indicating a higher state of health or well-being. This widely used measure of impairments in ADL has shown good reliability and validity (Aaronson et al., 1998; Steward et al., 1998).

- The Extended Glasgow Outcome Scale (GOS-E) that scores functional outcome with a series of questions covering consciousness, independence inside and outside the home, major social roles (work, social and leisure activities, family and friendships), and return to normal life. The final rating is based on the lowest category of outcome indicated by the responses. Traditionally, the GOS-E is scored by a semi-structured interview, but it was shown that reliable outcomes can also be obtained when the format of a self-report questionnaire is used (Hudak et al., 2005; Wilson et al., 1998).

- One item of the SF-36 ("Compared to one year ago, how would you rate your health in general now?") to rate perceived health change. Patients responded using a 5-point rating scale ranging from "much better" to "much worse." Scores were transformed into a 0-100 scale, where a score of 50 indicated no changes in health compared with one year ago (Steward et al., 1998).

\section{Statistical Analysis}

Data analyses were performed using SPSS software version 12.0 (SPSS Inc., Chicago, IL). All effects were tested at the $p<0.05$ level (two-tailed). Since responses on most outcome measures were not normally distributed, a natural $\log$ transformation was performed on the outcome measures to correct for skewness. Analyses of variance were used for between-group comparisons. When a significant main effect was found, post-hoc analyses were performed using the Bonferroni correction. Because the groups were not matched, analyses were adjusted for age and gender. In the tables below, unadjusted scores are presented. Chi-square analyses were used in the case of dichotomous variables.

\section{RESULTS}

\section{Response Analysis}

MTBI patients. All 618 eligible MTBI patients presented at the ED during the study period were sent a questionnaire six months post trauma. Forty-four envelopes were returned as undeliverable. In total, 299 patients returned a completed questionnaire, which constitutes an overall response rate of 52\%. Respondents were significantly older than non-responders (36.0 vs. 33.3, $F(1,573)=7.4, p=0.007)$ and more often women $(34 \%$ vs. $\left.23 \%, \chi^{2}=8.9, p=0.003\right)$. There were no differences between the groups with regard to the admission GCS and mechanism of injury.

Controls. Questionnaires were sent to 431 consecutive patients presented at the ED with an ankle or wrist distortion during 2003. Four envelopes were returned as un- 


\section{STULEMEIJER ET AL.}

deliverable. Completed questionnaires were returned by 261 patients, constituting an overall response rate of $61 \%$. A higher proportion of the respondents was female (55\% vs. $\left.37 \%, \chi^{2}=13.5, p<0.001\right)$, but there were no age effects.

\section{Patient Characteristics}

Table 1 shows the differences between the MTBI respondents with and those without additional injuries with respect to demographic variables and injury characteristics. Traffic-related accidents were common, especially in patients with additional injuries. Most patients with additional injuries had been admitted to the hospital, whereas this was less than half for the isolated MTBI patients. Besides more severe injuries to other parts of the body, the patients with additional injuries proved to have suffered more severe trauma to the head, as shown by a higher prevalence of PTA, retrograde amnesia (RA), a lower GCS on admission, and more frequent brain CT abnormalities. To control for potential influence of MTBI severity on outcome, we included the AIS Head score as a covariate in all further analysis. On ED admission, patients with isolated MTBI more frequently reported headache and nausea. The groups did not differ regarding the prevalence of LOC, dizziness or alcohol or drugs intoxication. Compared to the control group, the MTBI patients were significantly older (36.12 vs. 33.2, $F(1,559)=7.6, p=0.006)$ and more patients were male ( $75 \%$ vs. $\left.45 \%, \chi^{2}=25.9, p=0.0001\right)$. All control patients had an AIS Extremities score of 1.

\section{Six-Month Outcomes}

Table 2 summarizes the scores of the three patient groups on all outcome measures. As a group, the MTBI patients reported higher impairments in daily functioning and more severe postconcussional symptoms than the

Table 1. Demographic and Injury Characteristics for the MTBi Patients with and without Additional Injury ${ }^{a}$

\begin{tabular}{|c|c|c|c|c|c|}
\hline & \multicolumn{4}{|c|}{ MTBI } & \multirow[b]{2}{*}{$\mathrm{p}$-value } \\
\hline & \multicolumn{2}{|c|}{ Additional injury } & \multicolumn{2}{|c|}{ Isolated injury } & \\
\hline \multicolumn{6}{|l|}{ Demographics } \\
\hline$n$ & 89 & & 210 & & \\
\hline Age & $37.9(12.0)$ & & $35.2(12.3)$ & & $0.078^{\mathrm{b}}$ \\
\hline Male & 66 & $74 \%$ & 132 & $63 \%$ & $0.059^{\mathrm{c}}$ \\
\hline Mechanism of injury & & & & & $0.0001^{\mathrm{c}}$ \\
\hline Traffic & 66 & $74 \%$ & 96 & $46 \%$ & \\
\hline Falls & 17 & $19 \%$ & 61 & $29 \%$ & \\
\hline Violence & 2 & $2 \%$ & 25 & $12 \%$ & \\
\hline Other & 4 & $5 \%$ & 28 & $13 \%$ & \\
\hline Alcohol/drug intoxication $(n=296)$ & $20 / 88$ & $23 \%$ & $54 / 208$ & $26 \%$ & $0.557^{\mathrm{c}}$ \\
\hline Admission to hospital & 84 & $94 \%$ & 83 & $40 \%$ & $0.0001^{\mathrm{c}}$ \\
\hline Loss of consciousness $(n=236)$ & $30 / 59$ & $51 \%$ & $102 / 177$ & $58 \%$ & $0.387^{\mathrm{c}}$ \\
\hline Post-traumatic amnesia $(n=281)$ & $64 / 82$ & $78 \%$ & $128 / 199$ & $64 \%$ & $0.025^{\mathrm{c}}$ \\
\hline Retrograde amnesia $(n=264)$ & $34 / 73$ & $47 \%$ & $52 / 191$ & $27 \%$ & $0.002^{\mathrm{c}}$ \\
\hline \multicolumn{6}{|l|}{ Glasgow Coma Score } \\
\hline 13 & 5 & $6 \%$ & 5 & $2 \%$ & \\
\hline 14 & 14 & $16 \%$ & 17 & $8 \%$ & \\
\hline 15 & 70 & $79 \%$ & 188 & $90 \%$ & \\
\hline Brain CT abnormalities $(n=231)$ & $20 / 82$ & $24 \%$ & $21 / 149$ & $14 \%$ & $0.047^{\mathrm{c}}$ \\
\hline AIS head & $2.3(0.8)$ & range $1-5$ & $1.9(0.7)$ & $1-4$ & $0.0001^{\mathrm{b}}$ \\
\hline ISS, including head & $14.5(7.4)$ & range $5-41$ & $4.7(3.4)$ & range $1-17$ & $0.0001^{\mathrm{b}}$ \\
\hline ISS, excluding head & $8.8(6.4)$ & range $4-41$ & $0.4(0.5)$ & range $0-2$ & $0.0001^{\mathrm{b}}$ \\
\hline Headache $(n=293)$ & $24 / 87$ & $28 \%$ & $113 / 206$ & $55 \%$ & $0.0001^{\mathrm{c}}$ \\
\hline Nausea $(n=294)$ & $8 / 87$ & $9 \%$ & $52 / 207$ & $25 \%$ & $0.002^{\mathrm{c}}$ \\
\hline Dizziness $(n=294)$ & $3 / 86$ & $4 \%$ & $17 / 208$ & $8 \%$ & $0.147^{\mathrm{c}}$ \\
\hline
\end{tabular}

an case data was unknown or missing, the number of patients with complete data is presented between brackets, and data are presented as number/total number known.

${ }^{\mathrm{b}, \mathrm{c}}$ The $p$-value represents differences for patients with and without additional injuries by (b) univariate analysis of variance (ISS and AIS scores are adjusted for age and gender) or (c) $\chi^{2}$ analysis.

MTBI, mild traumatic brain injury; AIS, Abbreviated Injury Score; ISS, Injury Severity Score. 
Table 2. Six-Month Outcomes for the MTBI Patients with ANd without Additional Injuries and the Minor-Injury Controls

\begin{tabular}{|c|c|c|c|c|c|c|c|c|}
\hline & \multicolumn{4}{|c|}{ MTBI } & & & \multirow[b]{2}{*}{$\mathrm{p}-$ Value $^{\mathrm{b}, \mathrm{c}}$} & \multirow[b]{2}{*}{ Post-hoc ${ }^{\mathrm{d}}$} \\
\hline & \multicolumn{2}{|c|}{ Additional } & \multicolumn{2}{|c|}{ Isolated } & \multicolumn{2}{|c|}{ Controls } & & \\
\hline \multicolumn{9}{|l|}{ Global outcome } \\
\hline Glasgow Outcome Scale-E & & & & & & & $0.0001^{\mathrm{c}}$ & - \\
\hline Moderately disability (5/6) & 29 & $33 \%$ & 27 & $13 \%$ & \multicolumn{2}{|c|}{ n.a. ${ }^{\mathrm{e}}$} & & \\
\hline Good recovery $(7 / 8)$ & 60 & $67 \%$ & 183 & $87 \%$ & \multicolumn{2}{|c|}{ n.a. ${ }^{\mathrm{e}}$} & & \\
\hline Changes in occupation ${ }^{\mathrm{a}}$ & 31 & $35 \%$ & 29 & $14 \%$ & 5 & $2 \%$ & $0.0001^{\mathrm{c}}$ & - \\
\hline Current treatment & 39 & $44 \%$ & 30 & $14 \%$ & 14 & $5 \%$ & $0.0001^{\mathrm{c}}$ & - \\
\hline \multicolumn{9}{|l|}{ Psychosocial outcome } \\
\hline SF-36 Physical functioning ${ }^{\mathrm{f}}$ & \multicolumn{2}{|c|}{$72.4(28.7)$} & \multicolumn{2}{|c|}{$84.2(22.6)$} & \multicolumn{2}{|c|}{$88.5(17.6)$} & $0.0001^{\mathrm{b}}$ & 2 \\
\hline SF-36 Social functioning ${ }^{\mathrm{f}}$ & \multicolumn{2}{|c|}{$65.9(32.7)$} & \multicolumn{2}{|c|}{$74.6(27.6)$} & \multicolumn{2}{|c|}{$87.8(20.1)$} & $0.0001^{\mathrm{b}}$ & 2 \\
\hline SF-36 Health changeg & \multicolumn{2}{|c|}{$32.4(25.5)$} & \multicolumn{2}{|c|}{$41.0(22.6)$} & \multicolumn{2}{|c|}{$50.4(16.2)$} & $0.0001^{\mathrm{b}}$ & 2 \\
\hline \multicolumn{9}{|l|}{ Rivermead symptom clusters } \\
\hline Physical & \multicolumn{2}{|c|}{$23.7(24.4)$} & \multicolumn{2}{|c|}{$23.0(28.7)$} & \multicolumn{2}{|c|}{$4.8(12.3)$} & $0.0001^{\mathrm{b}}$ & 1 \\
\hline Affective & \multicolumn{2}{|c|}{$27.5(32.5)$} & \multicolumn{2}{|c|}{$23.5(30.2)$} & \multicolumn{2}{|c|}{$6.0(15.9)$} & $0.0001^{\mathrm{b}}$ & 1 \\
\hline Cognitive & \multicolumn{2}{|c|}{$31.4(33.5)$} & \multicolumn{2}{|c|}{$27.4(32.8)$} & \multicolumn{2}{|c|}{$4.7(15.5)$} & $0.0001^{\mathrm{b}}$ & 1 \\
\hline
\end{tabular}

aDefined as loss of work or change of working status into partial employment or other lower-level occupation due to the accident.

b,c The $p$-values represent differences between patient groups by (b) univariate analysis of variance adjusted for age, gender, and AIS-Head, or (c) $\chi^{2}$ analysis.

${ }^{\mathrm{d}}$ Post-hoc comparisons: $1=$ MTBI (Additional injury $=$ Isolated $)>$ controls $(p<0.001), 2=$ MTBI Additional injury $<$ MTBI Isolated $<$ controls $(p<0.001)$.

${ }^{\mathrm{e}}$ n.a. $=$ data were not available.

fSF-36 Physical/Social functioning: higher scores indicate a higher state functioning. SF-36 Dutch population norms (mean \pm SD): Physical functioning $=85.2 \pm 23.1 /$ Social functioning $=85.1 \pm 21.5$.

${ }^{g}$ SF-36 Health change: a score of 50 indicates no change, lower scores indicate a decrease in perceived health compared to one year ago. SF-36 Dutch population norm $($ mean $\pm \mathrm{SD})=52.6 \pm 18.3$.

MTBI, mild traumatic brain injury.

controls. Limitations in physical, social, and occupational functioning were especially prevalent in the MTBI patients with additional injuries. In contrast, no differences were found between the two MTBI subgroups as to the severity of affective, cognitive, or physical postconcussional symptoms.

\section{Association between Current Treatment Status and Outcome}

Almost half of the patients with additional injuries were still in some form of treatment at time of the study, compared to $14 \%$ of patients with isolated MTBI and 5\% of the control patients. To investigate the relation between treatment status and outcome, we divided each patient group in those that were in treatment and those that were not. As shown in Table 3, current treatment was strongly associated with more physical and social impairments, greater negative health change and more severe postconcussion symptoms. Moreover, there was a significant interaction effect between group and treatment status for all postconcussional symptom clusters. Whereas in all three groups, patients in treatment reported more postconcussional-like symptoms, this difference was especially large in patients with isolated MTBI. The MTBI patients with and without additional injuries that were not in treatment showed very similar functional outcome and equal levels of postconcussion-like symptoms. More specifically, they generally reported good global outcome and physical functioning scores comparable to population norms. Nevertheless, MTBI patients who were not in treatment still reported lower social functioning than the population norms, and more severe postconcussionlike symptoms than the minor-injury orthopedic controls.

\section{Impact of Location and Severity of Additional Extracranial Injury}

Of the 89 MTBI patients who sustained additional injury, injuries to the extremities were most frequent $(n=$ $53)$ followed by injuries to the face $(n=32)$, chest $(n=$ $21)$, abdomen $(n=8)$, and external $(n=1)$. Twenty-two patients suffered significant injuries to two or more AIS areas besides the injury to the head, and in 13 patients, 
STULEMEIJER ET AL.

Table 3. Comparison between Patients with and without Current Treatment on Six-Month Outcomes for the MTBI Patients with and without Additonal Injuries and the Minor-Injury Controls

\begin{tabular}{|c|c|c|c|c|c|c|c|c|c|c|c|c|}
\hline \multirow[b]{3}{*}{ Current treatment } & \multicolumn{8}{|c|}{ MTBI } & \multicolumn{4}{|c|}{ Controls } \\
\hline & \multicolumn{4}{|c|}{ Additional } & \multicolumn{4}{|c|}{ Isolated } & \multirow{2}{*}{\multicolumn{2}{|c|}{$\begin{array}{c}\text { Yes } \\
(\mathrm{n}=12)\end{array}$}} & \multirow[b]{2}{*}{$\begin{array}{c}N o \\
(\mathrm{n}=249)\end{array}$} & \multirow[b]{2}{*}{$\mathrm{p}-$ Value $e^{\mathrm{b}, \mathrm{c}}$} \\
\hline & \multicolumn{2}{|c|}{$\begin{array}{c}\text { Yes } \\
(\mathrm{n}=39)\end{array}$} & \multicolumn{2}{|c|}{$\begin{array}{c}N o \\
(\mathrm{n}=50)\end{array}$} & \multicolumn{2}{|c|}{$\begin{array}{c}\text { Yes } \\
(\mathrm{n}=29)\end{array}$} & \multicolumn{2}{|c|}{$\begin{array}{c}N o \\
(\mathrm{n}=181)\end{array}$} & & & & \\
\hline \multicolumn{13}{|l|}{ Type of treatment } \\
\hline Physical therapy & 26 & $67 \%$ & & & 12 & $41 \%$ & & & 12 & $100 \%$ & & \\
\hline Psychological support & 5 & $13 \%$ & & & 4 & $14 \%$ & & & - & & & \\
\hline Medical specialist & 4 & $10 \%$ & & & 5 & $17 \%$ & & & - & & & \\
\hline Other & 4 & $10 \%$ & & & 8 & $28 \%$ & & & - & & & \\
\hline \multicolumn{13}{|l|}{ Global outcome } \\
\hline GOSE-E & & & & & & & & & & & & $0.0001^{\mathrm{c}}$ \\
\hline Moderate disability $(5 / 6)$ & 22 & $56 \%$ & 7 & $14 \%$ & 20 & $69 \%$ & 5 & $3 \%$ & n.a & a. ${ }^{\mathrm{e}}$ & n.a. ${ }^{\mathrm{e}}$ & \\
\hline Good recovery $(7 / 8)$ & 17 & $44 \%$ & 43 & $86 \%$ & 9 & $31 \%$ & 176 & $97 \%$ & n.a & $a^{e}$ & n.a. ${ }^{\mathrm{e}}$ & \\
\hline Changes in occupation ${ }^{\mathrm{a}}$ & 21 & $54 \%$ & 9 & $18 \%$ & 18 & $62 \%$ & 11 & $6 \%$ & 3 & $25 \%$ & $2 \quad 1 \%$ & $0.0001^{\mathrm{c}}$ \\
\hline \multicolumn{13}{|l|}{ Psychosocial outcome } \\
\hline SF-36 Physical functioninge & 53.2 & $(30.4)$ & 87.8 & $(15.0)$ & 64.2 & $(27.3)$ & 87.9 & (19.6) & 62.3 & $3(27.5)$ & $90.1(15.7)$ & $0.0001^{\mathrm{b}}$ \\
\hline SF-36 Social functioninge & 50.3 & $(32.8)$ & 78.3 & $(27.0)$ & 57.9 & (31.9) & 78.0 & $(25.6)$ & 77.5 & $5(26.4)$ & $88.4(19.6)$ & $0.0001^{b}$ \\
\hline SF-36 Health change ${ }^{f}$ & 21.8 & $(20.8)$ & 40.8 & $(25.9)$ & 25.8 & $(29.0)$ & 44.1 & $(20.0)$ & 46.7 & $7(26.5)$ & $50.6(46.7)$ & $0.0001^{b}$ \\
\hline \multicolumn{13}{|l|}{ Rivermead symptom clusters } \\
\hline Physical & 28.2 & $(23.6)$ & 19.8 & $(25.0)$ & 50.9 & $(33.6)$ & 18.2 & $(25.1)$ & 15.2 & $2(26.6)$ & $4.4(11.0)$ & $0.0001^{\mathrm{b}, \mathrm{d}}$ \\
\hline Affective & 36.9 & (33.9) & 19.3 & (29.4) & 54.3 & $(36.1)$ & 18.1 & $(25.7)$ & 15.1 & $1(27.6)$ & $5.6(15.2)$ & $0.0001^{\mathrm{b}, \mathrm{d}}$ \\
\hline Cognitive & 39.1 & (36.4) & 25.2 & $(30.3)$ & 56.0 & $(38.2)$ & 22.7 & $(29.5)$ & 10.4 & $4(21.7)$ & $4.4(15.1)$ & $0.0001^{\mathrm{b}, \mathrm{d}}$ \\
\hline
\end{tabular}

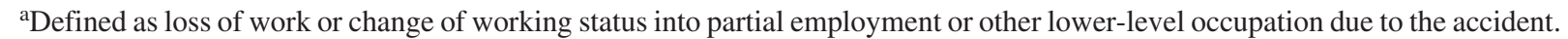

${ }^{\mathrm{b}, \mathrm{c}}$ The $p$-values represent main effects of treatment status with (b) univariate analysis of variance adjusted for age, gender, and AIS-Head. Main effects between patient groups are displayed in Table 2 or (c) $\chi^{2}$ analysis.

${ }^{\mathrm{d} P o s t-h o c ~ c o m p a r i s o n s: ~ s i g n i f i c a n t ~ i n t e r a c t i o n ~ b e t w e e n ~ p a t i e n t ~ g r o u p ~ a n d ~ t r e a t m e n t ~ s t a t u s ~}(p>0.01)$.

en.a. = data were not available.

fSF-36 Physical/Social functioning: higher scores indicate a higher state functioning. SF-36 Dutch population norms (mean \pm $\mathrm{SD})$ : Physical functioning $=85.2 \pm 23.1 /$ Social functioning $=85.1 \pm 21.5$.

${ }^{\mathrm{g}} \mathrm{SF}-36$ Health change: a score of 50 indicates no change, lower scores indicate a decrease in perceived health compared to one year ago. SF-36 Dutch population norm $($ mean $\pm \mathrm{SD})=52.6 \pm 18.3$.

MTBI, mild traumatic brain injury.

injuries were severe (ISS $>15)$. Tentative analyses were conducted to explore the role of the location and severity of the additional injury on 6-month outcome. Six months after injury, $75 \%$ of the patients with facial injuries and $82 \%$ of those with axial injuries reported good recovery on the GOSE, compared to $57 \%$ of patients with extremity injury and $59 \%$ of patients with multiple injuries, these differences however did not reach significance $\left(\chi^{2}=5.7, p=0.127\right)$. Significant effects of location of injury were found in physical functioning assessed with the SF-36 $(F(3,85)=5.1, p=0.003)$. Post-hoc analysis showed that patients with facial injuries do not report physical impairments $(90.5 \pm 13.8)$, whereas patients with multiple injuries $(61.8 \pm 33.3)$ or injuries to either the extremities $(65.5 \pm 30.4)$ or chest/abdomen (76.6 \pm 22.2$)$ still report substantial impairments. In case of severe injury (ISS $>15$ ), more limitations in physical functioning were reported (mean $58.4 \pm 31.9$ vs. $76.4 \pm$ 23.9, $F(3,85)=8.8, p=0.003)$, whereas no differences were found regarding the other outcome variables. There were no significant differences between both location or severity of additional injuries on severity of postconcussional symptoms or social functioning.

\section{DISCUSSION}

One third of the MTBI patients in our sample had suffered additional injuries, with injuries to the extremities being the most frequent, followed by injuries to the face and chest. In line with previous research in MTBI patients, the presence of extracranial injuries was strongly 


\section{IMPACT OF EXTRACRANIAL INJURIES ON MTBI OUTCOME}

associated with inferior levels of physical functioning, lower return-to-work rates, and poorer global outcome 6 months after trauma (Dikmen et al., 1994; Stambrook et al., 1990; van der Naalt et al., 1999). Outcome was poorest in patients who had suffered from injuries to the extremities and in those with injuries to multiple body areas besides the head. Overall, no differences were found in the severity of cognitive, physical, or emotional postconcussional symptoms between the patients with and those without additional injury, which is in accordance with findings from studies using injury severity scores in regression analyses (Bohnen et al., 1994; Paniak et al., 2002; Savola et al., 2003).

However, the results of the present study suggest that differences in outcome between patients with and without additional injuries also depends on treatment status at time of the assessment. MTBI patients with and without additional injuries who were not in treatment 6 months after injury both showed good physical functioning and good global outcome. Despite good physical recovery, these patients nevertheless reported more limitations in social functioning and more severe postconcussion-like symptoms than the minor-injury orthopedic controls. Conversely, patients who were in treatment at the time of the study reported poorer outcome on all outcome measures. In all three patients groups, those in treatment reported more postconcussion-like symptoms than those not in treatment. Interestingly, this difference was especially large in patients with isolated MTBI and not in the ones with additional injuries, as would be expected if functional limitations would indeed lead to more severe postconcussion-like symptoms complaints (Binder, 1986; Iverson et al., 1997; Kibby et al., 1997; Satz et al., 1999). Potentially, patients with additional injuries who are still in the process of recovering from their extracranial injuries are less likely to report the more subtle postconcussion-like symptoms. The follow-up period needs to be extended to determine whether the report of postconcussional symptoms in the MTBI patients with additional injuries increases or decreases once physical disabilities have been resolved.

Besides more severe extracranial injuries, patients with additional injuries also seemed to have suffered a somewhat more severe impact to the head. However, head injury severity did not have significant influence on any of the outcome measures, which supports previous findings suggesting that there is no linear relationship between injury severity and the subsequent development of postconcussional symptoms (Middleboe et al., 1992; Ponsford et al., 2000). Since our study did not include non-TBI controls with severe physical injuries, no inferences about the cause of the postconcussion-like symptoms can be drawn (Satz et al., 1999). To clarify the controversies sur- rounding the diagnosis of postconcussional syndrome, these assumptions deserve further scrutiny.

Based on the results of this study, we strike a cautionary note for studies that use symptoms reported on admission to the ED as outcome predictors. Previous studies suggested that acute symptoms like nausea may have important predictive value for delayed outcome (de Kruijk et al., 2002; Rutherford, 1989; Savola et al., 2003; Stalnacke et al., 2004). However, in our study, patients with additional injuries were less likely to report sensations of nausea and headache at the ED. This may be explained by the more frequent use of analgesic medication in this group, and potentially, given the prominence of their additional injuries, from underreporting of symptoms related to the relatively mild head trauma. Accordingly, we believe that acute injury characteristics cannot be reliably determined in MTBI patients with additional injuries who receive analgesic or sedative medication, and should therefore not be used as predictors of outcome in this subgroup of patients.

Overall, MTBI patients reported more impairments in daily functioning and higher levels of postconcussional symptoms than the controls with mere ankle or wrist distortions. This finding corresponds with the results of other outcome studies in ED-admitted MTBI patients which showed that, although good recovery is common, some patients will still experience postconcussional symptoms months after injury (Bohnen et al., 1994; Dacey et al., 1991; de Kruijk et al., 2002; Ponsford et al., 2000). Moreover, the commonly held assumption that most MTBI patients have returned to their premorbid level of functioning after 3-6 months after trauma does not hold true for many patients with additional injuries, and a longer follow-up is necessary to investigate final outcome in these patients. As expected, most patients in the control group had recovered well.

As the response rate in our study only just exceeded $50 \%$, one should be cautious when extrapolating the findings to the general population. Respondents differed from non-responders with respect to age and gender. However, considering the large sample size and the finding that none of these factors had substantially affected the outcomes, we do believe that the results are representative of a general MTBI population as seen in EDs. Since we relied on questionnaires to assess outcome and did not perform structured interviews or actual neuropsychological testing, no formal diagnosis of post-concussional syndrome could be made. Furthermore, the interpretation of the scores on the GOS-E we used to evaluate the patients' overall outcome was fraught in the patients with additional injuries since the instrument does not allow a distinction between impairments due to brain injury and impairments resulting from extracranial injuries. However, we feel we 


\section{STULEMEIJER ET AL.}

have successfully circumvented this bias by including several other validated questionnaires assessing outcome.

In conclusion, we demonstrated that patients with MTBI and additional extracranial injuries report inferior functional outcomes 6 months after trauma relative to patients with an isolated MTBI, but equal levels of postconcussional symptoms overall. For many patients, especially those with additional injuries, 6 months is too early to determine final outcome, and the follow-up needs to be expanded. These results suggest that, for the prediction of recovery from MTBI, both for clinical as well as research purposes, it is imperative to take the presence of concurrent injuries into account.

\section{ACKNOWLEDGMENTS}

We would like to thank all the patients for their participation and Cécile Ziedses des Plantes for assisting in the data management. The Top Center Traumatology Nijmegen is kindly acknowledged for their financial support of the reported study.

\section{REFERENCES}

AARONSON, N.K., MUllER, M., COHEN, P.D., et al. (1998). Translation, validation, and norming of the Dutch language version of the SF-36 Health Survey in community and chronic disease populations. J. Clin. Epidemiol. 51, 1055-1068.

BAKER, S.P., ONEILL, B., HADDON, W., and LONG, W.B. (1974). Injury Severity Score-method for describing patients with multiple injuries and evaluating emergency care. J. Trauma 14, 187-196.

BARTH, J.T., MACCIOCCHI, S.N., GIORDANI, B., RIMEL, R., JANE, J.A., and BOLL, T.J. (1983). Neuropsychological sequelae of minor head injury. Neurosurgery 13, 529-533.

BINDER, L.M. (1986). Persisting symptoms after mild headinjury-A review of the postconcussive syndrome. J. Clin. Exp. Neuropsychol. 8, 323-346.

BINDER, L.M., ROHLING, M.L., and LARRABEE, J. (1997). A review of mild head trauma. Part I: Meta-analytic review of neuropsychological studies. J. Clin. Exp. Neuropsychol. 19, 421-431.

BOHNEN, N., VAN ZUTPHEN, W., TWIJNSTRA, A., WIJNEN, G., BONGERS, J., and JOLLES, J. (1994). Late outcome of mild head injury: results from a controlled postal survey. Brain Inj. 8, 701-708.

BOHNEN, N.I., JOLLES, J., TWIJNSTRA, A., MELLINK, R., and WIJNEN, G. (1995). Late neurobehavioural symptoms after mild head injury. Brain Inj. 9, 27-33.
CASSIDY, J.D., CARROLL, L.J., PELOSO, P.M., et al. (2004). Incidence, risk factors and prevention of mild traumatic brain injury: results of the WHO Collaborating Centre Task Force on Mild Traumatic Brain Injury. J. Rehabil. Med. 43, S28-S60.

DACEY, R., DIKMEN, S., TEMKIN, N., MCLEAN, A., ARMSDEN, G., and WINN, H.R. (1991). Relative effects of brain and non-brain injuries on neuropsychological and psychosocial outcome. J. Trauma 31, 217-222.

DE KRUIJK, J.R., LEFFERS, P., MENHEERE, P.P.C.A., MEERHOFF, S., RUTTEN, J., and TWIJNSTRA, A. (2002). Prediction of post-traumatic complaints after mild traumatic brain injury: early symptoms and biochemical markers. J. Neurol. Neurosur. Psychiatry 73, 727-732.

DIKMEN, S.S., TEMKIN, N.R., MACHAMER, J.E., HOLUBKOV, A.L., FRASER, R.T., and WINN, H.R. (1994). Employment following traumatic head injuries. Arch. Neurol. Chic. 51, 177-186.

HUDAK, A.M., CAESAR, R.R., FROL, A.B., et al. (2005). Functional outcome scales in traumatic brain injury: a comparison of the glasgow outcome scale (extended) and the functional status examination. J. Neurotrauma 22, 1319-1326.

HUGENHOLTZ, H., STUSS, D.T., STETHEM, L.L., and RICHARD, M.T. (1988). How long does it take to recover from a mild concussion? Neurosurgery 22, 853-858.

IVERSON, G.L., and MCCRACKEN, L.M. (1997). "Postconcussive" symptoms in persons with chronic pain. Brain Inj. 11, 783-790.

KIBBY, M.Y. and LONG, C.J. (1997). Effective treatment of minor head injury and understanding its neurological consequences. Appl. Neuropsychol. 4, 34-42.

KING, N.S., CRAWFORD, S., WENDEN, F.J., CALDWELL, F.E., and WADE, D.T. (1999). Early prediction of persisting post-concussion symptoms following mild and moderate head injuries. Br. J. Clin. Psychol. 38, 15-25.

KING, N.S., CRAWFORD, S., WENDEN, F.J., MOSS, N.E., and WADE, D.T. (1995). The Rivermead Post Concussion Symptoms Questionnaire: a measure of symptoms commonly experienced after head injury and its reliability. J. Neurol. 242, 587-592.

LEVIN, H.S., MATTIS, S., RUFF, R.M., et al. (1987). Neurobehavioral outcome following minor head injury: a threecenter study. J. Neurosurg. 66, 234-243.

MACCIOCCHI, S.N., BARTH, J.T., and LITTLEFIELD, L.M. (1998). Outcome after mild head injury. Clin. Sports Med. $17,27-36$.

McCAULEY, S.R., BOAKE, C., LEVIN, H.S., CONTANT, C.F., and SONG, J.X. (2001). Postconcussional disorder following mild to moderate traumatic brain injury: anxiety, depression, and social support as risk factors and comorbidities. J. Clin. Exp. Neuropsychol. 23, 792-808. 


\section{IMPACT OF EXTRACRANIAL INJURIES ON MTBI OUTCOME}

MIDDLEBOE, T., ANDERSEN, H.S., BIRKET-SMITH, M., and FRIIS, M.L. (1992). Minor head injury: impact on general health after 1 year. A prospective follow-up study. Acta Neurol. Scand. 85, 5-9.

MOONEY, G., SPEED, J., and SHEPPARD, S. (2005). Factors related to recovery after mild traumatic brain injury. Brain Inj. 19, 975-987.

PANIAK, C., REYNOLDS, S., PHILIPS, K., TOLLER-LOBE, G., MELNYK, A., and NAGY, J. (2002). Patient complaints within 1 month of mild traumatic brain injury: A controlled study. Arch. Clin. Neuropsychol. 17, 319-334.

PONSFORD, J., WILLMOTT, C., ROTHWELL, A., et al. (2000). Factors influencing outcome following mild traumatic brain injury in adults. J. Int. Neuropsychol. Soc. 6, 568-579.

RUTHERFORD, W. (1989). Postconcussion symptoms: relation to acute neurological indices, individual differences, and circumstances of injury, in: Mild Head Injury. Levin, H.S., Eisenberg, H.M., and Benton, A.L. (eds). Oxford University Press: New York, pps. 217-240.

SATZ, P., ALFANO, M.S., LIGHT, R., et al. (1999). Persistent post-concussive syndrome: a proposed methodology and literature review to determine the effects, if any, of mild head and other bodily injury. J. Clin. Exp. Neuropsychol. 21, 620-628.

SAVOLA, O., and HILLBOM, M. (2003). Early predictors of post-concussion symptoms in patients with mild head injury. Eur. J. Neurol. 10, 175-181.

STALNACKE, B.M., TEGNER, Y., and SOJKA, P. (2004). Playing soccer increases serum concentrations of the biochemical markers of brain damage S-100B and neuron-spe- cific enolase in elite players: a pilot study. Brain Inj. 18, 899-909.

STAMBROOK, M., MOORE, A.D., PETERS, L.C., DEVIAENE, C., and HAWRYLUK, G.A. (1990). Effects of mild, moderate and severe closed head injury on long-term vocational status. Brain Inj. 4, 183-190.

STEWARD, A.L., HAYDS, R.D., and WARE, J.E., JR. (1998). The MOS short form general health survey: reliability and validity in a patient population. Med. Care 26, 724-735.

VAN DER NAALT, N.J., VAN ZOMEREN, A.H., SLUITER, W.J., and MINDERHOUD, J.M. (1999). One year outcome in mild to moderate head injury: the predictive value of acute injury characteristics related to complaints and return to work. J. Neurol. Neurosurg. Psychiatry 66, 207-213.

VOS, P.E., BATTISTIN, L., BIRBAMER, G., et al. (2002). EFNS guideline on mild traumatic brain injury. Report of an EFNS Task Force. Eur. J. Neurol. 9, 207-219.

WILSON, J.T.L., PETTIGREW, L.E.L., and TEASDALE, G.M. (1998). Structured interviews for the Glasgow Outcome Scale and the extended Glasgow Outcome Scale: Guidelines for their use. J. Neurotrauma 15, 573-585.

Address reprint requests to: Pieter E. Vos, M.D., Ph.D. Department of Neurology Radboud University Nijmegen Medical Centre P.O. Box 9101 $6500 \mathrm{HB}$, Nijmegen, The Netherlands

E-mail: P.Vos@neuro.umcn.nl 